\title{
GALANIN (1-15)-FLUOXETINE INTERACTION IN THE NOVEL OBJECT RECOGNITION TEST. INVOLVEMENT OF 5-HT1A RECEPTORS IN THE PREFRONTAL CORTEX OF THE RATS
}

Antonio Flores-Burgess ${ }^{1}$, Carmelo Millón ${ }^{1}$, Belen Gago ${ }^{1}$, Laura García-

Durán ${ }^{1}$, Noelia Cantero-García ${ }^{1}$, Rafael Coveñas ${ }^{2}$, José Angel Narváez ${ }^{1}$, Kjell Fuxe ${ }^{3}$, Luis Santín ${ }^{4}$, \& Zaida Díaz-Cabiale ${ }^{1}$

1.Universidad de Málaga, Instituto de Investigación Biomédica de Málaga, Facultad de Medicina, Campus de Teatinos s/n, 29071 Málaga, Spain.

2. University of Salamanca, Institute of Neurosciences of Castilla and León Laboratory of Neuroanatomy of the Peptidergic Systems (INCYL), Salamanca, Spain.

3. Department of Neuroscience, Karolinska Institute, Stockholm, Sweden.

4.Universidad de Málaga, Instituto de Investigación Biomédica de Málaga, Facultad de Psicología, Campus de Teatinos s/n, 29071 Málaga, Spain.

*Corresponding author:

Z. Díaz-Cabiale

Departmento de Fisiologia

Facultad de Medicina

Universidad de Málaga

Campus de Teatinos s/n. 29080 Málaga, Spain.

Tel.: + 34-952137246

E-mail: zaida@uma.es

Running tittle: Galanin(1-15)/Fluoxetine interaction in mPFC 


\section{Abstract}

Galanin (1-15) [GAL(1-15)] participates in mood regulation and depression. GAL(115 ) is also able to enhance the antidepressant effects induced by Fluoxetine (FLX) in the forced swimming test through interaction between GALR1-GALR2 and 5-HT1A receptors that induced changes in the binding characteristics and mRNA of the 5HT1AR in the hippocampus.

Since the medial prefrontal cortex (mPFC) is a core region for the interaction between emotional processing and cognition with a high density of 5-HT1AR and GALR1 and GALR2, we have analyzed the binding characteristics and mRNA levels of 5-HT1AR in the mPFC after GAL(1-15)-FLX administration in the rats. GAL(1-15) increased the $\mathrm{Kd}$ and the Bmax of the 5HT1AR agonist binding in the mPFC as well as the mRNA levels of 5-HT1AR in mPFC. Moreover, GAL(1-15) reversed the effects of memory impairment induced by $\mathrm{FLX}(10 \mathrm{mg} / \mathrm{Kg})$ in the Novel Object Recognition task. GALR2 was involved in these effects, since the specific GALR2 antagonist M871 blocked GAL(1-15) mediated actions at behavioral level. On the contrary GAL(1-15) did not reverse the effect of FLX in the Object Location Memory task.

In conclusion, our results describe an interactions between GAL(1-15) and FLX in the mPFC involving interactions at the 5-HT1AR receptor level in the plasma membrane with changes at the transcriptional level with implications also at functional level. The GALR1-GALR2-5-HT1A heteroreceptor could be postulated to be used to reverse some of the adverse effects of FLX on memory processes. 


\section{GALANIN (1-15)-FLUOXETINE INTERACTION IN THE NOVEL OBJECT RECOGNITION TEST. INVOLVEMENT OF 5-HT1A RECEPTORS IN THE PREFRONTAL CORTEX OF THE RATS}

Antonio Flores-Burgess ${ }^{1}$, Carmelo Millón ${ }^{1}$, Belen Gago ${ }^{1}$, Laura García-Durán ${ }^{1}$, Noelia Cantero-García ${ }^{1}$, Rafael Coveñas ${ }^{2}$, José Angel Narváez ${ }^{1}$, Kjell Fuxe ${ }^{3}$, Luis Santín ${ }^{4}$, \& Zaida Díaz-Cabiale ${ }^{1}$

1.Universidad de Málaga, Instituto de Investigación Biomédica de Málaga, Facultad de Medicina, Campus de Teatinos s/n, 29071 Málaga, Spain.

2. University of Salamanca, Institute of Neurosciences of Castilla and León Laboratory of Neuroanatomy of the Peptidergic Systems (INCYL), Salamanca, Spain.

3. Department of Neuroscience, Karolinska Institute, Stockholm, Sweden.

4. Universidad de Málaga, Instituto de Investigación Biomédica de Málaga, Facultad de Psicología, Campus de Teatinos s/n, 29071 Málaga, Spain.

*Corresponding author:

Z. Díaz-Cabiale

Departmento de Fisiologia

Facultad de Medicina

Universidad de Málaga

Campus de Teatinos s/n. 29080 Málaga, Spain.

Tel.: + 34-952137246

E-mail: zaida@uma.es

Running tittle: Galanin(1-15)/Fluoxetine interaction in mPFC 


\section{Abstract}

Galanin (1-15) [GAL(1-15)] participates in mood regulation and depression. GAL(1-15) is also able to enhance the antidepressant effects induced by Fluoxetine (FLX) in the forced swimming test through interaction between GALR1-GALR2 and 5-HT1A receptors that induced changes in the binding characteristics and mRNA of the 5-HT1AR in the hippocampus.

Since the medial prefrontal cortex (mPFC) is a core region for the interaction between emotional processing and cognition with a high density of 5-HT1AR and GALR1 and GALR2, we have analyzed the binding characteristics and mRNA levels of 5-HT1AR in the mPFC after GAL(1-15)-FLX administration in the rats. GAL(1-15) increased the $\mathrm{Kd}$ and the Bmax of the 5HT1AR agonist binding in the mPFC as well as the mRNA levels of 5-HT1AR in mPFC. Moreover, GAL(1-15) reversed the effects of memory impairment induced by FLX $(10 \mathrm{mg} / \mathrm{Kg})$ in the Novel Object Recognition task. GALR2 was involved in these effects, since the specific GALR2 antagonist M871 blocked GAL(1-15) mediated actions at behavioral level. On the contrary GAL(1-15) did not reverse the effect of FLX in the Object Location Memory task.

In conclusion, our results describe an interactions between GAL(1-15) and FLX in the mPFC involving interactions at the 5-HT1AR receptor level in the plasma membrane with changes at the transcriptional level with implications also at functional level. The GALR1-GALR2-5-HT1A heteroreceptor could be postulated to be used to reverse some of the adverse effects of FLX on memory processes. 


\section{Introduction}

Galanin (GAL) is a neuropeptide (Tatemoto et al., 1983) widely distributed in neurons within the Central Nervous System (CNS) (Jacobowitz et al., 2004). Three GAL receptor (GALR1-3 receptors) subtypes with high affinity for GAL have been cloned (Branchek et al., 2000; Mitsukawa et al., 2008). GALR1 and GALR2 receptors are found in many regions of the CNS as demonstrated with in situ hybridization, radioligand binding and immunohistochemical studies (Jacobowitz et al., 2004). GALR1 and GALR3 mainly activate inhibitory G proteins $\mathrm{Gi} / \mathrm{Go}$, while GALR2 mainly couples to $\mathrm{Gq} / \mathrm{G} 11$ to mediate excitatory signaling (Branchek et al., 2000; Wang et al., 1997).

These three GALR are involved in a number of central functions modulating neuroendocrine, pain control, cardiovascular, addiction and food intake (DiazCabiale et al., 2010; Mitsukawa et al., 2008; Picciotto, 2010) GAL also participates in mood regulation and depression (Bellido et al., 2002; Juhasz et al., 2014; Weiss et al., 1998). The activation of GALR1 and GALR3 results in a depression like behavior while stimulation of GALR2 leads to anti-depressantlike effects (Bartfai et al., 2004; Kuteeva et al., 2008; Lu et al., 2005). Moreover, GAL modulates 5-HT1A receptor (5-HT1AR) function at autoreceptor and postsynaptic level in the brain (Fuxe et al., 1988; Hedlund and Fuxe, 1996; Kehr et al., 2002; Misane et al., 1998; Razani et al., 2000; Razani et al., 2001). Recent results indicate that this interaction could be in part due to the existence of GALR1-5-HT1AR heteroreceptor complexes in discrete brain regions (Borroto-Escuela et al., 2010; Fuxe et al., 2012). It has been suggested that in depression, the GALR1-5-HT1AR heteroreceptor complexes is dysfunctional which may lead to disturbances in meso-limbic 5-HT neurotransmission (Borroto-Escuela et al., 2017; Borroto-Escuela et al., 2018).

Not only GAL but also the N-terminal fragments like GAL(1-15) are active in the central nervous system (CNS) (Diaz-Cabiale et al., 2007; Diaz-Cabiale et al., 
2010; Diaz-Cabiale et al., 2005; Flores-Burgess et al., 2017; Millon et al., 2017; Millon et al., 2016; Millon et al., 2015). Recently we described that GAL(1-15) induces strong depression-related and anxiogenic-like effects in rats and these effects were significantly stronger than the ones induced by GAL (Millon et al., 2015). The receptor for GAL(1-15) is the GALR1-GALR2 isoreceptor dimer (Borroto-Escuela et al., 2014; Millon et al., 2015) for which GAL(1-15) has a high affinity. The strong depression-like and anxiogenic-like effects of GAL(115) disappeared in the siRNA GALR1 and siRNA GALR2 receptor knockdown rats (Millon et al., 2015) and were related to the disappearance of the in situ PLA signals and, thus, to the disappearance of the GALR1-GALR2 isoreceptor complexes (Millon et al., 2015).

GAL(1-15) is also able to enhance the antidepressant effects induced by the 5HT1AR agonist 8-OH-DPAT in the forced swimming test (FST) (Millon et al., 2016), effect that was again significantly stronger than the ones induced by GAL. Importantly, the mechanism underlying this action involved interactions at the receptor level in the plasma membrane with changes also at the transcriptional level. GAL(1-15) increased the $\mathrm{Kd}$ and Bmax values and the mRNA levels of the postjunctional 5-HT1AR in the dorsal hippocampus but not of the 5-HT1A autoreceptors in the DR (Millon et al., 2016). The 5-HT1A autoreceptor complexes appear to be differentially regulated since a reduction of mRNA levels in the DR was observed. The putative existence of a trimeric GALR1-GALR2-5-HT1AR heteroreceptor complex was therefore postulated which can help explain this interesting enhancement by GAL(1-15) of the antidepressant effects of 8-OH-DPAT (Borroto-Escuela et al., 2018; Millon et al., 2016) and underlie as a mechanism of action independent from GAL.

In line with these results, GAL(1-15) and not GAL enhanced the antidepressant effects of the SSRI fluoxetine (FLX) using the FST (Flores-Burgess et al., 2017). In the combined treatment with GAL(1-15) and FLX, the modulation of the 5HT1AR agonist binding sites in the dentate gyrus was also different from the 
modulation found with GAL(1-15). The modulation by combined treatment with FLX and GAL(1-15) produced an increased affinity of the 5-HT1AR agonist binding sites and a reduction of their Bmax values in the dentate gyrus (FloresBurgess et al., 2017), in contrast to the reduced affinity and increased Bmax levels found in this region with GAL(1-15) (Millon et al., 2016). However, the increase in 5-HT1AR mRNA levels in the hippocampus was still obtained after the combined treatment with GAL(1-15) and FLX, as found after treatment with GAL(1-15) alone (Flores-Burgess et al., 2017).

These results illustrate that GAL(1-15) can produce differential changes in mood from depressive to antidepressant actions, being dependent on how the GALR come together with the 5-HT1AR. The molecular complexes are likely highly dynamic and vary from one brain region to another.

The serotonergic system is also implicated in the neurobiological control of learning and memory (Meneses, 2007). One of the serotoninergic receptors more extensively studied in behavioural learning paradigms is the 5-HT1AR (Meneses et al., 2007; Ogren et al., 2008). For example, in the Novel Object Recognition task, the systemic administration of the 5-HT1AR specific agonist 8-OH-DPAT in rats impaired the recognition of the new object, and the antagonist WAY100635 blocked these deficits (Meneses et al., 2007; Pitsikas et al., 2003).

The role of medial prefrontal cortex (mPFC) in single-item recognition memory is not fully dilucidated. Initial studies showed that large aspiration lesions of the MPFC produced delay dependent impairments in delayed non-matching to sample tasks (Ragozzino et al., 2002; Warburton and Brown, 2015), suggesting an involvement for mPFC in this process (Morici et al., 2015), but excitotoxic lesion studies indicate that the mPFC is not involved in the NOR task based on single-item recognition memory. (Warburton and Brown, 2015). However, other studies using more 
functional approaches, based mainly in the activation of immediate early genes (IEGs), have showed that the mPFC increases the expression of $c$ Fos (Rinaldi et al., 2010; Castilla-Ortega et al., 2012) and Zif-268 (Freitas Barbosa et al., 2013) in response to the test phase in a NOR task, supporting that this region is involved at least in the retrieval of this recognition memory

Since the mPFC has been recently identified as a core region for the interaction between emotional processing and cognition (Ray and Zald, 2012) with a particular a high density of 5-HT1AR and GALR1 and GALR2 (Jacobowitz et al., 2004; Pompeiano et al., 1992, 1994), we have analyzed the binding characteristics and mRNA levels of 5-HT1AR in the mPFC after GAL(1-15)-FLX administration. Moreover, we have studied the effect of GAL(1-15) on FLXmediated behavioural responses using two memory tasks where FLX effect has been previously described (Ampuero et al., 2013; Castane et al., 2015), the Novel Object Recognition (NOR) and the Object Location Memory (OLM). In both tasks FLX treatment did not affect learning or short-term memory but specifically impaired long-term memories since animals did not explore the new objects in the test session performed $24 \mathrm{~h}$ post-training either in the OLM or in the NOR tasks (Ampuero et al., 2013; Castane et al., 2015). In addition, we tested the involvement of GALR2 in the GAL(1-15) effect with the selective GALR2 antagonist M871.

\section{Material and Methods}

\subsection{Animals}

Male Sprague Dawley rats (body weight 225-250g) were obtained from CRIFFA, Barcelona and maintained in a $12 \mathrm{~h}$ dark/light cycle under controlled conditions of humidity $(55-60 \%)$ and temperature $\left(22 \pm 2^{\circ} \mathrm{C}\right)$. The animals had free access to food pellets and tap water. Behavioral tests were performed during the light phase of the cycle. All Experimental procedures were approved 
by the Institutional Animal Ethics Committee of the University of Málaga, Spain.

\subsection{Stereotaxic surgery}

This protocol has been described previously (Diaz-Cabiale et al., 2011). Briefly, the rats were anesthetized intraperitoneally with equitesin $(3.3 \mathrm{ml} / \mathrm{kg}$ body weight). A chronic 22-gauge stainless-steel guide cannula was stereotaxically implanted into the right lateral cerebral ventricle $(+1.4 \mathrm{~mm}$ lateral, $-1 \mathrm{~mm}$ posterior to bregma, and 3.6mm below the surface of the skull) (Paxinos, 1986). Animals were individually housed after surgery and had a recovery period of 7 days prior to behavioural test.

\subsection{Administration of substances and drugs}

In the experimental groups we used the following drugs: Fluoxetine hydrochloride (Sigma-Aldrich, San Luis, EEUU) and GAL(1-15) and the GALR2 antagonist M871 (TOCRIS, Bristol, Reino Unido). Intracerebroventricular (icv) administration of substances was performed for one minute in a volume of $5 \mu \mathrm{l}$ using a 26-gauge stainless-steel injection cannula connected to a Hamilton siringe via PE-10 tubing with special care that during the process the dilutions were administered fluently and without overflowing. All rats that received the i.c.v. injections were assumed to have proper cannula placement and none were excluded. The solutions were prepared using artificial cerebrospinal fluid (aCSF). For subcutaneous (sc) administration of Fluoxetine (FLX), solutions was prepared using distillate water for improving the solubility in a volume of $2 \mathrm{ml} / \mathrm{Kg}$ (Lopez-Rubalcava and Lucki, 2000).

\subsection{Double Immunofluorescence}

The procedures have been previously used (Millon et al., 2015). Primary antibody rabbit anti-GAL2 receptor (Alomone Lab, 1/250) was incubated for 12 hours at $4^{\circ} \mathrm{C}$ and detected with the red secondary antibody mouse anti-rabbit DyLight 549 (Jackson inmunoResearch Laboratories, 1/100). Goat anti-GAL1 receptor (Santa Cruz Biotechnology INC, EEUU, 1:250) was incubated 12 hours 
at $4^{\circ} \mathrm{C}$ and detected with the secondary antibody rabbit biotynilated anti-goat (Vector Labs Inc.) and Alexa Fluor 488-conjugated Streptavidin (Jackson Laboratories InmunoResearch, 1:1000). Sections were mounted on slides with fluorescent mounting medium (Dako) and visualized using a Leica SP8 confocal microscope. The double immunolabeling was performed in the tissue of rats without treatment.

\subsection{Autoradiography and in situ hybridization histochemistry}

The procedure to perform receptor autoradiography and in situ hybridization histochemistry was previously described (Flores-Burgess et al., 2017; Millon et al., 2016; Saenz del Burgo et al., 2013). 6 rats per group received three sc injections of FLX or vehicle at 23, 5 and $\mathbf{1 . 2 5} \mathrm{h}$ prior to the sacrifice, and GAL(115 ) or aCSF was administered by a single injection via icv 30 minutes before sacrifice. In these experiments we have used groups of animals that did not perform object recognition tasks. We have used the doses and injection schedule based on our previous work where we observed that the coadministration of FLX and GAL(1-15) modified the binding characteristics and mRNA expression of 5-HT1AR in the dentate gyrus (Flores-Burgess et al., 2017; Millon et al., 2016; Millon et al., 2015).

The pattern of FLX injection was shown to produce effects in the FST similar to those obtained after chronic treatment and to those leading to its clinical effects in humans (Detke et al., 1997; Estrada-Camarena et al., 2003; EstradaCamarena et al., 2006). Their brains were rapidly removed and frozen in $-40^{\circ} \mathrm{C}$ isopenthane and stored at $-80^{\circ} \mathrm{C}$ until its use. Coronal sections $(14 \mu \mathrm{m}$ thick) were cut in a cryostate at bregma levels, according to the atlas of (Paxinos, 1986) (medial prefrontal cortex (mPFC): $3.50 \mathrm{~mm}$ to $2.70 \mathrm{~mm}$ ), thaw-mounted on gelatin-coated slides stored at $-20^{\circ} \mathrm{C}$ until further processing.

\subsubsection{Quantitative autoradiography}

Saturation experiments were performed using [3H]-8-OH-DPAT (specific activity: $142 \mathrm{Ci} / \mathrm{mmol}$, Perkin Elmer, Walthman, Massachusetts) in 
concentrations ranging from 0.24 to $10.8 \mathrm{nM}$. In each saturation experiment, two groups of ten sections were prepared in order to perform the total binding and the non-specific binding. Nonspecific binding was defined as the binding of [3H]-8-OH-DPAT in the presence of 10-5M of 5-HT (Sigma Aldrich, St. Louis, $\mathrm{CA})$. The brain sections were preincubated for 30 minutes at room temperature in $50 \mathrm{mM}$ Tris- $\mathrm{HCl}$ buffer ( $\mathrm{pH} 7.6)$, containing $4 \mathrm{mM} \mathrm{CaCl} 2,0.01 \%$ ascorbic acid and $10 \mathrm{mM}$ pargyline. The sections were then incubated for 60 minutes at room temperature with $[3 \mathrm{H}]-8-\mathrm{OH}-\mathrm{DPAT}$ in the same solution as above. Thereafter, the sections were washed twice for 5 minutes in ice cold buffer and rinsed briefly in ice-cold destilled water before being dried under a stream of cold air. Dried sections were exposed to [3H]- Kodak Biomax-MR (Sigma Aldrich, St. Louis, CA) for 6 weeks along with [3H]-radiolabeled standards plastic strips (Amersham, UK).

\subsubsection{In situ hybridization histochemistry}

For in situ hybridization studies, frozen tissue sections were air-dried at room temperature and fixed in 4\% paraformaldehyde during 20 minutes and washed in phosphate-buffered saline (PBS 1X: 8mM Na2HPO4, 1.4mM KH2PO4, $136 \mathrm{mM} \mathrm{NaCl}, 2.6 \mathrm{mM} \mathrm{KCl}$ ) for $5 \mathrm{~min}$ in $3 X$ PBS at room temperature and twice for 5 min each in $1 \mathrm{X}$ PBS, then were incubated in a freshly prepared solution of predigested pronase (Calbiochem, San Diego, USA) at a final concentration of $24 \mathrm{U} / \mathrm{ml}$ in $50 \mathrm{mM}$ Tris- $\mathrm{HCl}, \mathrm{pH} 7.5,5 \mathrm{mM}$ EDTA. The enzymatic activity was stopped by immersion for $30 \mathrm{~s}$ in $2 \mathrm{mg} / \mathrm{mL}$ glycine in $1 \mathrm{X}$ PBS. Tissues were finally rinsed in 1X PBS and dehydrated through a graded series of ethanol. The oligonucleotides used were complementary to the following base sequences and were custom-synthesized by Isogen Bioscience (Maarsden, The Netherlands): 5HT1A, 1-48, 763-810 and 1219-1266 [Gen Bank acc. No NM_012585.1]. The oligonucleotides were labeled at their 3 '-end by using [33P]dATP (3000 Ci/mmol) and terminal deoxynucleotidyl-transferase (TdT,

Oncogene Research Products, San Diego, CA, USA), and purified using MicroSpin G-50 columns (Amersham, UK). For hybridization, 
radioactivelylabeled probes were diluted to a final concentration of $206 \mathrm{cpm} / \mathrm{mL}$ in a solution containing $50 \%$ formamide, 4 X SSC (1X SSC: $150 \mathrm{mM} \mathrm{NaCl}$, $15 \mathrm{mM}$ sodium citrate), $1 \mathrm{X}$ Denhardt's solution $(0.02 \%$ Ficoll, $0.02 \%$ polyvinylpyrrolidone, $0.02 \%$ bovine serum albumin), $10 \%$ dextran sulfate, $1 \%$ sarkosyl, $20 \mathrm{mM}$ phosphate buffer $\mathrm{pH} 7.0,250 \mu \mathrm{g} / \mathrm{mL}$ yeast tRNA and $500 \mu \mathrm{g} / \mathrm{mL}$ salmon sperm DNA. Tissues were covered with $80 \mu \mathrm{L}$ of the hybridization solution and overlaid with Nescofilm (Bando Chemical Inc., Kobe, Japan) coverslips to prevent evaporation. Sections were incubated in humid boxes overnight at $42^{\circ} \mathrm{C}$ and then washed 4 times $(45 \mathrm{~min}$ each) in $600 \mathrm{mM} \mathrm{NaCl}$, $10 \mathrm{mM}$ Tris- $\mathrm{HCl}, \mathrm{pH} 7.5,1 \mathrm{mM}$ EDTA at $60^{\circ} \mathrm{C}$ and once in the same buffer at room temperature for $30 \mathrm{~min}$. Hybridized sections were exposed to Kodak BIOMAX-MR film (Sigma Aldrich, St. Louis, CA) for 10 days at $-70^{\circ} \mathrm{C}$ with intensifying screens.

\subsubsection{Image analysis}

Measurements using the Image system ( $\mathrm{NIH}$, USA) were made in the distinctly labelled region in the mPFC using a square as a sampling field $(0.3 \mathrm{~mm} 2)$. One observation per region and rat was obtained, since the average of the measurements was calculated. [3H]-radiolabeled standards plastic strips (Amersham, UK) were used to convert the grey values into $\mathrm{fmol} / \mathrm{mg}$ protein values in the receptor binding quantitative autoradiography. The semiquantitative evaluations of the in situ hybridization autoradiograms were performed based on the optical density (O.D.).

\subsection{Object Location Memory (OLM) and Novel Object Recognition (NOR) task}

OLM and NOR were performed in an open field test apparatus $(100 \times 100 \mathrm{~cm})$ under dim light. The task procedures consist of three phases: habituation, training, and test (Ampuero et al., 2013) (Fig. 1). The animals were handled 2 days before the habituation phase. In the habituation phase, animals were allowed to explore the open field 10 minutes. $24 \mathrm{~h}$ later, in the test phase, two identical objects (two plastic boats $20 \mathrm{~cm}$ high and filled with water) were placed 
in two opposite corners of the apparatus $10 \mathrm{~cm}$ from the side wall and the animals were allowed to explore during 3 minutes. The day after we performed the test phase. For the NOR task we change one object to other differently shaped and colored, the objects were of similar in weight and size (Fig 1A). In the OLM we use the same objects employed in the training phase changing the location of one of them (Fig 1B). Animals were allowed to explore 3 minutes in the test phase. Exploration was defined as sniffing or touching the object with the nose and/or forepaws. Turning around or sitting on the object was not considered as exploratory behavior. The time spent by the rats exploring each object, familiar $(\mathrm{F})$ or new $(\mathrm{N})$, in the test phase was recorded by a video camera and was analyzed blind to the treatment. A discrimination index (DI) was calculated as: $\mathrm{DI}=(\mathrm{N}-\mathrm{F}) /(\mathrm{N}+\mathrm{F})$, this ratio represent the difference in exploration time expressed as a proportion of the total time spent exploring the two objects (Ennaceur and Delacour, 1988). We also analyzed the locomotor activity using the video-tracking software EthovisionXT (Noldus, Wageningen, Nederland). Between trials, the role of familiar or new object and the relative position were counterbalanced and randomly permuted also the open field and the objects were cleaned thoroughly in every phase (Akirav and Maroun, 2006; Ampuero et al., 2013). The pharmacological treatments were administered between the training and test phases.

\subsubsection{Behavioural assessment}

Different groups of rats were assessed in the NOR and OLM. In the first set of experiment in order to evaluate the interaction of FLX with $\mathrm{GAL}(1-15)$ in the NOR task, groups of rats received before the test phase three injections $(23,5$ and $1 \mathrm{~h})$ of sc FLX $(10 \mathrm{mg} / \mathrm{kg})$ or vehicle and a single icv injection of a threshold dose of GAL(1-15)(1nmol) or aCSF 15 minutes before the test. We also determined the involvement of GALR2 in the effect of GAL(1-15) on FLXmediated action in rats that received three injections of sc FLX $(10 \mathrm{mg} / \mathrm{kg})$, a single icv injection of GAL(1-15)(1nmol) and the GALR2 antagonist M871 (3nmol) icv in combination. In the second set of experiments we evaluate the 
interaction of FLX with GAL(1-15) in the OLM task, groups of rats received three injections of $\mathrm{FLX}(10 \mathrm{mg} / \mathrm{Kg})$ alone or in combination with $\mathrm{GAL}(1-15)(1 \mathrm{nmol})$.

\subsection{Statistical analysis}

Data are presented as the mean \pm SEM and samples number $(n)$ are indicated in figure legends. All data were analyzed using GraphPad PRISM 6.0 (GraphPad Software, La Jolla, CA). One-way analysis of variance (ANOVA) followed by Newman-Keuls comparison post hoc-test was performed. Differences were considered significant at $p<0.05 \quad\left({ }^{*} p<0.05,{ }^{* *} p<0.01\right.$, $\left.{ }^{* * *} p<0.001\right)$. The data from the saturation experiments were analyzed by nonlinear regression analysis for the determination of the dissociation constant (Kd) and the total number of agonist binding sites (Bmax) using GraphPad PRISM 4.0.

\section{Results}

\subsection{Neurochemical effects}

3.1.2. 5-HT1AR agonist radioligand binding. Saturation curves.

An extensive colocalization of GALR1 and GALR2 immunoreactivities was observed in the nerve cells of the mPFC (Fig. 2).

In the autoradiographic experiments, the coadministration of the three injections of sc FLX $(10 \mathrm{mg} / \mathrm{kg})$ and a single icv injection of GAL(1-15)(1nmol) produced a significant increase in the $\mathrm{Kd}$ value (Fig. $3 \mathrm{~A} ; \mathrm{F}_{3,20}=14.36$, $p<0.001$; post hoc $p<0.01$ ) and in the Bmax value (Fig. $3 B ; F_{3,18}=5.57, p<0.01$; post hoc $p<0.05$ ) of the agonist radioligand $[3 \mathrm{H}]-8-\mathrm{OH}-\mathrm{DPAT}$ compared with $\mathrm{FLX}(10 \mathrm{mg} / \mathrm{Kg})$ in the mPFC. Representative autoradiograms with a low radioligand concentration $(1 \mathrm{nM})$ illustrate the decrease of labelling (increase in Kd values) in the mPFC $30 \mathrm{~min}$ after the coadministration of the three injections of sc FLX $(10 \mathrm{mg} / \mathrm{kg})$ and a single icv injection of GAL(1-15)(1nmol) (Fig. 3C). 


\subsubsection{5-HT1AR mRNA levels}

In the In situ hybridization experiments, the coadministration of the three sc injections of $F L X(10 \mathrm{mg} / \mathrm{kg})$ and a single icv injection of $\operatorname{GAL}(1-15)(1 \mathrm{nmol})$ produced a significant increase in the 5-HT1AR mRNA levels in the mPFC (Fig. $4 A ; F_{3,19}=6.418$, $p<0.01$; post hoc $\left.p<0.01\right)$ compared with $F L X(10 \mathrm{mg} / \mathrm{Kg})$ group. Representative autoradiograms illustrate the increase of 5-HT1AR mRNA levels in the mPFC, after the coadministration of the three sc injections of FLX $(10 \mathrm{mg} / \mathrm{kg})$ and a single icv injection of GAL(1-15)(1 $\mathrm{nmol})$ (Fig. 4B).

\subsection{Behavioral effects}

\subsubsection{NOR}

The overall one way ANOVA revealed a significant effect between treatments in $\mathrm{DI}$ in the NOR task (Fig. 5; $\mathrm{F}_{3,18}=6.393$, $\mathrm{p}<0.01$ ).

The coadministration of the three sc injections of FLX $(10 \mathrm{mg} / \mathrm{kg})$ and a single icv injection of GAL(1-15)(1nmol) reversed the effects of memory impairment induced by FLX $(10 \mathrm{mg} / \mathrm{Kg}$ ) alone (Fig. 5; post hoc $p<0.05)$ in the NOR showing the same DI values as the control group.

In agreement with other studies where FLX induces an impairment memory effects in the NOR when tested at $24 \mathrm{~h}$ post training phase (Ampuero et al., 2013; Castane et al., 2015), our pattern of administration of FLX with three injections given sc at $10 \mathrm{mg} / \mathrm{kg}$ between the training and test phase also induced the same effects in this task (Fig. 5 ; post hoc p<0.05).

In the same experiment we tested the involvement of the GALR2 in the GAL(115)-FLX(10 mg/kg) interaction with the selective GALR2 antagonist M871. M871(3nmol) blocked the effects of GAL(1-15) over FLX in the NOR task since the coadministration of the three sc injections of $F L X(10 \mathrm{mg} / \mathrm{kg})$ and a single icv injection of GAL(1-15)(1nmol) in combination with M871(3nmol) induced a significant reduction of the $\mathrm{DI}$ (Fig. 5; post hoc $\mathrm{p}<0.05$ ) compared with the group of animals treated with $\mathrm{FLX}(10 \mathrm{mg} / \mathrm{Kg})$ plus $\mathrm{GAL}(1-15)(1 \mathrm{nmol})$. 
No pharmacological treatment used in the NOR task in this experiment significantly modified the analyzed parameters of locomotor activity (Table1A; $\left.F_{2,14}=0.19 ; p=0.828\right)$ and the total time of exploration (Table1A; $F_{2,14}=2.19$; $p=0.148$ ) in the test phase.

In the training phase, the total object exploration time confirmed that there was no difference in the baseline exploration levels between the groups (Table 2).

The administration of a single icv injection of GAL(1-15)(1nmol) or M871(3nmol) alone did not modified any parameter analyzed in the NOR task: DI (Table 1B; $F_{2,18}=0.097 ; p=0.907$ ), locomotor activity (Table $1 B ; F_{2,18}=0.144 ; p=0.866$ ), total time of exploration (Table 1B; $F_{2,18}=0.67 ; p=0.524$ ).

\subsubsection{OLM}

The coadministration of the three sc injections of FLX $(10 \mathrm{mg} / \mathrm{kg})$ and a single icv injection of $\operatorname{GAL}(1-15)(1 \mathrm{nmol})$ in this task potenciate FLX-action in the DI although it did not reach the statistical significance, indicating an opposite effect of GAL(1-15) than in the NOR task.

The sc administration of three injections of $F L X(10 \mathrm{mg} / \mathrm{Kg})$ between the training and test phase in the OLM task showed a reduction in the DI compared with the control group although it didn't reach the significance (Fig. 6; $F_{2,15}=3.24$, $p=0.0675$ ).

No pharmacological treatment used in the OLM task significantly modified the analyzed parameters of locomotor activity (Table1; $\left.F_{2,15}=2.03 ; p=0.165\right)$ and the total time of exploration (Table1; $F_{2,15}=0.174 ; p=0.841$ ) in the test phase.

\section{Discussion}


In the present work we described for the first time the interactions between GAL(1-15) and FLX in the mPFC involving interactions at the 5-HT1AR level in the plasma membrane with changes also at the transcriptional level. Thus, the coadministration of GAL(1-15) and FLX increased the $\mathrm{Kd}$ and the Bmax of the $5 \mathrm{HT} 1 \mathrm{AR}$ agonist binding in the mPFC as well as the mRNA levels of 5-HT1AR in mPFC. Moreover, GAL(1-15) reversed the effects of memory impairment induced by $F L X(10 \mathrm{mg} / \mathrm{Kg})$ in the Novel Object Recognition. GALR2 was involved in these effects, since the specific GALR2 antagonist M871 blocked GAL(1-15) mediated actions at behavioral level. On the contrary GAL(1-15) did not reverse the effect of FLX in the Object Location Memory.

We have described previously an interaction between GAL(1-15) and FLX; GAL(1-15) enhanced the antidepressant effects of FLX in the forced swim test (Flores-Burgess et al., 2017). The mechanism of this effect was explained on the bases of the existence of a trimeric GALR1-GALR2-5-HT1AR heteroreceptor complex (Borroto-Escuela et al., 2018; Flores-Burgess et al., 2017; Millon et al., 2016) since an increase in the mRNA levels of postjunctional 5-HT1AR in the dorsal hippocampus and a decrease in $\mathrm{Kd}$ and Bmax values, specifically in the dentate gyrus of the hippocampus was observed (FloresBurgess et al., 2017). Such heteroreceptor complexes could work as integrative nodes in 5-HT neurotransmission and as major targets for the antidepressant effects of GAL(1-15)+FLX at postjunctional level of 5-HT transmission of the raphe-hippocampal neurons (Fuxe et al., 2012; Fuxe et al., 2008; Millon et al., 2016).

Our results in the present paper suggest that the molecular complexes GALR1GALR2-5-HT1A are likely highly dynamic and vary from one brain region to another. In fact, GAL(1-15)+FLX administration induced the opposite effect in the modulation of 5-HT1AR in the mPFC compared to the dentate gyrus (Flores-Burgess et al., 2017), however the increase in 5-HT1AR mRN A levels in the mPFC was still obtained after the GAL(1-15)+FLX administration. It's 
interesting to highlight that the administration of FLX or GAL(1-15) alone did not change the Kd or the Bmax of 5-HT1AR neither the mRNA levels in the mPFC. This results are in agreement with our previous work (Li et al., 1997; FloresBurgess et al., 2017) and suggest that GAL(1-15) and FLX interact at membrane level in the mPFC to modify this parameters.

The differential effects observed with the combination of GAL(1-15)+FLX in the modulation of the 5-HT1AR recognition in the mPFC vs the hippocampus may be explained by differences in the composition of the 5-HT1AR heteroreceptor complexes involved in the two regions. This can lead to alterations in the allosteric receptor-receptor interactions and in the signaling of the heteroreceptor complexes. Also the adapter proteins in the heterocomplexes may differ between the two regions with consequences for the allosteric receptor-receptor interactions. It has also been described regional differences in the coupling of 5-HT1AR to $\mathrm{G}$ protein. $5-\mathrm{HT} 1 \mathrm{AR}$ interact equally with $\mathrm{G} \alpha_{0}$ and $G \alpha_{i 3}$ in the cerebral cortex but mainly with $G \alpha_{o}$ and weakly with $G \alpha_{i 3}$ in the hippocampus (Mannoury la Cour et al., 2006). Such differences may contribute to the opposite effect in the affinity and Bmax of the 5-HT1AR binding sites in the mPFC in contrast to the hippocampus (Borroto-Escuela et al., 2018; FloresBurgess et al., 2017).

Since FLX induced increases in extracellular levels of 5-HT likely increasing 5HT signaling not only over the 5-HT1AR receptor, but also over a number of other 5-HT receptor subtypes, the participation of other 5-HT receptor subtypes with high density in the mPFC such as 5-HT2A (Castane et al., 2015) in the interaction remains to be tested.

At behavioural level, the interaction between $G A L(1-15)+F L X$ was demonstrated in the NOR task. The NOR task was developed to provide a valid measure of memory function based upon spontaneous exploratory activity in the rat (Ennaceur et al., 1997). Object recognition can be assessed form the 
preference normal rats display for investigating novel rather than familiar complex objects having been characterized as declarative rather than nondeclarative memory task (Ennaceur et al., 1997).

The role of mPFC in single-item recognition memory is not fully dilucidated. Initial studies showed that large aspiration lesions of the mPFC produced delay dependent impairments in delayed non-matching to sample tasks (Ragozzino et al., 2002; Warburton and Brown, 2015), suggesting an involvement for mPFC in this process (Morici et al., 2015), but excitotoxic lesion studies indicate that the MPFC is not involved in the NOR task based on single-item recognition memory. (Warburton and Brown, 2015). However, other studies using more functional approaches, based mainly in the activation of immediate early genes (IEGs), have showed that the MPFC increases the expression of c-Fos (Rinaldi et al., 2010; Castilla-Ortega et al., 2012) and Zif-268 (Freitas Barbosa et al., 2013) in response to the test phase in a NOR task, supporting that this region is involved at least in the retrieval of this recognition memory. Moreover, other studies using intra-mPFC infusions of D1, D2 and D3 agonists and antagonist, were able to affect the long-term memory consolidation in a NOR task (Papp et al., 2017). All these results suggest that mPFC is involved in single-item recognition memory (NOR), and that its main role seems to be associated with both, memory retrieval and long-term memory consolidation (Frankland and Botempi 2005; Leon et al., 2010).

With the experimental design used in our study, where FLX was administered 23, 5 and $1 \mathrm{~h}$ and GAL(1-15) 15 min before memory retrieval phase in the NOR, it is clear that GAL(1-15) was able to counteract the impairment induced by FLX in this task, affecting the retrieval of a consolidated memory. In addition, this effect cannot be explained by the modulation of other memory phases as the acquisition or the retention. Interestingly, several results based in the use of IEGs, support the 
involvement of the MPFC in the retrieval phase in this task (Rinaldi et al., 2010; Castilla-Ortega et al., 2012; Freitas Barbosa et al., 2013), suggesting that likely GAL(1-15) is acting through the MPFC in order to modulates memory retrieval.

The fact that GAL(1-15) reversed the effects of memory impairment induced by $\mathrm{FLX}(10 \mathrm{mg} / \mathrm{Kg})$ in the NOR task could be associated with the proposed trimeric GALR1-GALR2-5-HT1AR heteroreceptor in the mPFC. Since GAL(1-15) acts through a GALR1-GALR2 heteroreceptor complexes that inhibits the $\mathrm{Gq} / \mathrm{G} 11$ mediated signaling of the GALR2 protomer and switches it towards Gi/omediated signaling enhancing Gi/o-mediated signaling of GALR1 in the GALR1GALR2 heterodimer (Borroto-Escuela et al., 2014; Millon et al., 2015), the mechanism for the GALR1-GALR2-5-HT1AR heteroreceptor complex in the mPFC could be explain on the bases that this enhancement of $\mathrm{Gi} / \mathrm{o}$-mediated signal will impair 5-HT1AR receptor signaling in the trimer complex explaining that the coadministration of GAL(1-15)+FLX reversed FLX-mediated effects. GALR2 is involved in the GAL(1-15) effects since the GALR2 antagonist M871 blocked the effects induced by GAL(1-15) on FLX-mediated effects.

FLX induces an impairment memory effects in the NOR when tested at $24 \mathrm{~h}$ post training phase (Ampuero et al., 2013; Castane et al., 2015), without any effect in the spontaneous motor behaviours (Ampuero et al., 2013). Our results with FLX are in agreement with these studies and confirm our pattern of administration of FLX and the behavioural model used.

On the contrary GAL(1-15) did not reverse the effect of FLX in the OLM task. In this task the rats are presented with two identical, familiar objects, one of which is in its previous location while the other is in a new location. Normal rats spontaneously spend more time exploring the object in the novel location (Ennaceur et al., 1997). The OLM task assess spatial memory in a less aversive manner than in the Morris water maze task (Akirav and Maroun, 2006; Ampuero 
et al., 2013).

Since the hippocampus is crucial in spatial memory tasks such as the OLM task (Barker and Warburton, 2011), the fact that GAL(1-15) did not reverse FLX action in the OLM task, its in agreement with previous results from our group that demonstrate that the GALR1-GALR2-5-HT1AR heteroreceptor in the hippocampus enhances 5-HT1AR receptor signaling in the complex by, inter alia, reducing 5-HT1AR internalization from the plasma membrane (BorrotoEscuela et al., 2018; Flores-Burgess et al., 2017).

Although several authors described the key role of the MPFC in the associative learning tasks based on the natural exploration as the NOR (Muller and Knigh, 2006; Meneses 2007) and the hippocampus as a crucial region in the OLM task (Barker and Warburton, 2011), we can no exclude the influence of other brain areas related to the regulation of both emotional and cognitive behaviors (Ampuero et al., 2013; Meneses 2007).

In conclusion, our results describes an interactions between GAL(1-15) and FLX in the mPFC involving interactions at the 5-HT1AR level in the plasma membrane with changes also at the transcriptional level and these interactions may be associated with the effects at functional level, since GAL(1-15) reversed the effects of memory impairment induced by FLX in the Novel Object Recognition. The target for GAL(1-15) may mainly be GALR1-GALR2-5-HT1AR heteroreceptor and confirmed that these molecular complexes are likely highly dynamic and vary from one brain region to another and can be used to reverse some of the adverse effects of FLX on memory processes.

\section{Funding and Disclosure}

This work was supported by grants awarded by Spanish Ministry of Economy (SAF2016-79008-P), PSI2017-82604-R (Grant BES-2014-068426), and by 
UMA postdoctoral program to C.M.

The authors declare no conflict of interest.

\section{References}

Akirav, I., Maroun, M., 2006. Ventromedial prefrontal cortex is obligatory for consolidation and reconsolidation of object recognition memory. Cereb Cortex 16, 1759-1765.

Ampuero, E., Stehberg, J., Gonzalez, D., Besser, N., Ferrero, M., Diaz-Veliz, G., Wyneken, U., Rubio, F. J., 2013. Repetitive fluoxetine treatment affects longterm memories but not learning. Behav Brain Res 247, 92-100.

Barbosa, F. F., Santos, J. R., Meurer, Y. S., Macedo, P. T., Ferreira, L. M., Pontes, I. M., Ribeiro, A. M., Silva, R. H., 2013. Differential Cortical c-Fos and Zif-268 Expression after Object and Spatial Memory Processing in a Standard or Episodic-Like Object Recognition Task. Front Behav Neurosci 7, 112.

Barker, G. R., Warburton, E. C., 2011. When is the hippocampus involved in recognition memory? J Neurosci 31, 10721-10731.

Bartfai, T., Lu, X., Badie-Mahdavi, H., Barr, A. M., Mazarati, A., Hua, X. Y., Yaksh, T., Haberhauer, G., Ceide, S. C., Trembleau, L., Somogyi, L., Krock, L., Rebek, J., Jr., 2004. Galmic, a nonpeptide galanin receptor agonist, affects behaviors in seizure, pain, and forced-swim tests. Proc Natl Acad Sci U S A 101, 10470-10475.

Bellido, I., Diaz-Cabiale, Z., Jimenez-Vasquez, P. A., Andbjer, B., Mathe, A. A., Fuxe, K., 2002. Increased density of galanin binding sites in the dorsal raphe in a genetic rat model of depression. Neurosci Lett 317, 101-105.

Borroto-Escuela, D. O., Carlsson, J., Ambrogini, P., Narvaez, M., Wydra, K., Tarakanov, A. O., Li, X., Millon, C., Ferraro, L., Cuppini, R., Tanganelli, S., Liu, F., Filip, M., Diaz-Cabiale, Z., Fuxe, K., 2017. Understanding the Role of GPCR Heteroreceptor Complexes in Modulating the Brain Networks in Health and Disease. Front Cell Neurosci 11, 37.

Borroto-Escuela, D. O., Narvaez, M., Ambrogini, P., Ferraro, L., Brito, I., Romero-Fernandez, W., Andrade-Talavera, Y., Flores-Burgess, A., Millon, C., Gago, B., Narvaez, J. A., Odagaki, Y., Palkovits, M., Diaz-Cabiale, Z., Fuxe, K., 2018. Receptor(-)Receptor Interactions in Multiple 5-HT1A Heteroreceptor Complexes in Raphe-Hippocampal 5-HT Transmission and Their Relevance for Depression and Its Treatment. Molecules 23.

Borroto-Escuela, D. O., Narvaez, M., Di Palma, M., Calvo, F., Rodriguez, D., Millon, C., Carlsson, J., Agnati, L. F., Garriga, P., Diaz-Cabiale, Z., Fuxe, K., 2014. Preferential activation by galanin 1-15 fragment of the GalR1 protomer of a GalR1-GalR2 heteroreceptor complex. Biochem Biophys Res Commun 452, 347-353.

Borroto-Escuela, D. O., Narvaez, M., Marcellino, D., Parrado, C., Narvaez, J. A., Tarakanov, A. O., Agnati, L. F., Diaz-Cabiale, Z., Fuxe, K., 2010. Galanin 
receptor-1 modulates 5-hydroxtryptamine-1A signaling via heterodimerization. Biochem Biophys Res Commun 393, 767-772.

Branchek, T. A., Smith, K. E., Gerald, C., Walker, M. W., 2000. Galanin receptor subtypes. Trends Pharmacol Sci 21, 109-117.

Castilla-Ortega, E., Pedraza, C., Chun, J., de Fonseca, F. R., Estivill-Torrus, G., Santin, L. J., 2012. Hippocampal c-Fos activation in normal and LPA(1)-null mice after two object recognition tasks with different memory demands. Behav Brain Res 232, 400-405.

Castane, A., Kargieman, L., Celada, P., Bortolozzi, A., Artigas, F., 2015. 5HT2A receptors are involved in cognitive but not antidepressant effects of fluoxetine. Eur Neuropsychopharmacol 25, 1353-1361.

Detke, M. J., Johnson, J., Lucki, I., 1997. Acute and chronic antidepressant drug treatment in the rat forced swimming test model of depression. Exp Clin Psychopharmacol 5, 107-112.

Diaz-Cabiale, Z., Parrado, C., Fuxe, K., Agnati, L., Narvaez, J. A., 2007. Receptor-receptor interactions in central cardiovascular regulation. Focus on neuropeptide/alpha(2)-adrenoreceptor interactions in the nucleus tractus solitarius. J Neural Transm (Vienna) 114, 115-125.

Diaz-Cabiale, Z., Parrado, C., Narvaez, M., Millon, C., Puigcerver, A., Fuxe, K., Narvaez, J. A., 2010. Neurochemical modulation of central cardiovascular control: the integrative role of galanin. EXS 102, 113-131.

Diaz-Cabiale, Z., Parrado, C., Narvaez, M., Puigcerver, A., Millon, C., Santin, L., Fuxe, K., Narvaez, J. A., 2011. Galanin receptor/Neuropeptide Y receptor interactions in the dorsal raphe nucleus of the rat. Neuropharmacology $61,80-$ 86.

Diaz-Cabiale, Z., Parrado, C., Vela, C., Razani, H., Covenas, R., Fuxe, K., Narvaez, J. A., 2005. Role of galanin and galanin(1-15) on central cardiovascular control. Neuropeptides 39, 185-190.

Ennaceur, A., Delacour, J., 1988. A new one-trial test for neurobiological studies of memory in rats. 1: Behavioral data. Behav Brain Res 31, 47-59.

Ennaceur, A., Neave, N., Aggleton, J. P., 1997. Spontaneous object recognition and object location memory in rats: the effects of lesions in the cingulate cortices, the medial prefrontal cortex, the cingulum bundle and the fornix. Exp Brain Res 113, 509-519.

Estrada-Camarena, E., Fernandez-Guasti, A., Lopez-Rubalcava, C., 2003. Antidepressant-like effect of different estrogenic compounds in the forced swimming test. Neuropsychopharmacology 28, 830-838.

Estrada-Camarena, E., Lopez-Rubalcava, C., Fernandez-Guasti, A., 2006. Facilitating antidepressant-like actions of estrogens are mediated by 5-HT1A and estrogen receptors in the rat forced swimming test. Psychoneuroendocrinology 31, 905-914.

Flores-Burgess, A., Millon, C., Gago, B., Narvaez, M., Borroto-Escuela, D. O., Mengod, G., Narvaez, J. A., Fuxe, K., Santin, L., Diaz-Cabiale, Z., 2017. Galanin (1-15) enhancement of the behavioral effects of Fluoxetine in the forced swimming test gives a new therapeutic strategy against depression. Neuropharmacology 118, 233-241. 
Frankland, P. W., Bontempi, B., 2005. The organization of recent and remote memories. Nat Rev Neurosci 6, 119-130.

Fuxe, K., Borroto-Escuela, D. O., Romero-Fernandez, W., Tarakanov, A. O., Calvo, F., Garriga, P., Tena, M., Narvaez, M., Millon, C., Parrado, C., Ciruela, F., Agnati, L. F., Narvaez, J. A., Diaz-Cabiale, Z., 2012. On the existence and function of galanin receptor heteromers in the central nervous system. Front Endocrinol (Lausanne) 3, 127.

Fuxe, K., Marcellino, D., Rivera, A., Diaz-Cabiale, Z., Filip, M., Gago, B., Roberts, D. C., Langel, U., Genedani, S., Ferraro, L., de la Calle, A., Narvaez, J., Tanganelli, S., Woods, A., Agnati, L. F., 2008. Receptor-receptor interactions within receptor mosaics. Impact on neuropsychopharmacology. Brain Res Rev 58, 415-452.

Fuxe, K., Ogren, S. O., Jansson, A., Cintra, A., Harfstrand, A., Agnati, L. F., 1988. Intraventricular injections of galanin reduces $5-\mathrm{HT}$ metabolism in the ventral limbic cortex, the hippocampal formation and the fronto-parietal cortex of the male rat. Acta Physiol Scand 133, 579-581.

Hedlund, P. B., Fuxe, K., 1996. Galanin and 5-HT1A receptor interactions as an integrative mechanism in 5-HT neurotransmission in the brain. Ann $\mathrm{N}$ Y Acad Sci 780, 193-212.

Jacobowitz, D. M., Kresse, A., Skofitsch, G., 2004. Galanin in the brain: chemoarchitectonics and brain cartography--a historical review. Peptides 25, 433-464.

Juhasz, G., Hullam, G., Eszlari, N., Gonda, X., Antal, P., Anderson, I. M., Hokfelt, T. G., Deakin, J. F., Bagdy, G., 2014. Brain galanin system genes interact with life stresses in depression-related phenotypes. Proc Natl Acad Sci U S A 111, E1666-1673.

Kehr, J., Yoshitake, T., Wang, F. H., Razani, H., Gimenez-Llort, L., Jansson, A., Yamaguchi, M., Ogren, S. O., 2002. Galanin is a potent in vivo modulator of mesencephalic serotonergic neurotransmission. Neuropsychopharmacology 27, 341-356.

Kuteeva, E., Hokfelt, T., Wardi, T., Ogren, S. O., 2008. Galanin, galanin receptor subtypes and depression-like behaviour. Cell Mol Life Sci 65, 18541863.

Leon, W. C., Bruno, M. A., Allard, S., Nader, K., Cuello, A. C., 2010. Engagement of the PFC in consolidation and recall of recent spatial memory. Learn Mem 17, 297-305.

Lopez-Rubalcava, C., Lucki, I., 2000. Strain differences in the behavioral effects of antidepressant drugs in the rat forced swimming test. Neuropsychopharmacology 22, 191-199.

Lu, X., Barr, A. M., Kinney, J. W., Sanna, P., Conti, B., Behrens, M. M., Bartfai, T., 2005. A role for galanin in antidepressant actions with a focus on the dorsal raphe nucleus. Proc Natl Acad Sci U S A 102, 874-879.

Mannoury la Cour, C., El Mestikawy, S., Hanoun, N., Hamon, M., Lanfumey, L., 2006. Regional differences in the coupling of 5-hydroxytryptamine-1A receptors to $G$ proteins in the rat brain. Mol Pharmacol 70, 1013-1021.

Meneses, A., 2007. Stimulation of 5-HT1A, 5-HT1B, 5-HT2A/2C, 5-HT3 and 5HT4 receptors or 5-HT uptake inhibition: short- and long-term memory. Behav 
Brain Res. 184, 81-90.

Millon, C., Flores-Burgess, A., Narvaez, M., Borroto-Escuela, D. O., Gago, B., Santin, L., Castilla-Ortega, E., Narvaez, J. A., Fuxe, K., Diaz-Cabiale, Z., 2017. The neuropeptides Galanin and Galanin(1-15) in depression-like behaviours. Neuropeptides 64, 39-45.

Millon, C., Flores-Burgess, A., Narvaez, M., Borroto-Escuela, D. O., Santin, L., Gago, B., Narvaez, J. A., Fuxe, K., Diaz-Cabiale, Z., 2016. Galanin (1-15) enhances the antidepressant effects of the 5-HT1A receptor agonist 8OHDPAT: involvement of the raphe-hippocampal 5-HT neuron system. Brain Struct Funct 221, 4491-4504.

Millon, C., Flores-Burgess, A., Narvaez, M., Borroto-Escuela, D. O., Santin, L., Parrado, C., Narvaez, J. A., Fuxe, K., Diaz-Cabiale, Z., 2015. A role for galanin $\mathrm{N}$-terminal fragment (1-15) in anxiety- and depression-related behaviors in rats. Int J Neuropsychopharmacol 18.

Misane, I., Razani, H., Wang, F. H., Jansson, A., Fuxe, K., Ogren, S. O., 1998. Intraventricular galanin modulates a 5 -HT1A receptor-mediated behavioural response in the rat. Eur $\mathrm{J}$ Neurosci 10, 1230-1240.

Mitsukawa, K., Lu, X., Bartfai, T., 2008. Galanin, galanin receptors and drug targets. Cell Mol Life Sci 65, 1796-1805.

Morici, J. F., Bekinschtein, P., Weisstaub, N. V., 2015. Medial prefrontal cortex role in recognition memory in rodents. Behav Brain Res 292, 241-251.

Müller, NG., Knight, RT., 2006. The functional neuroanatomy of working memory: contributions of human brain lesion studies. Neuroscience. 139, 51-58. Ogren, SO., Eriksson, TM., Elvander-Tottie, E., D'Addario, C., Ekström, JC,, Svenningsson, P., Meister, B., Kehr, J., Stiedl, O., 2008. The role of 5-HT(1A) receptors in learning and memory. Behav Brain Res. 195, 54-77.

Papp, M., Gruca, P., Lason-Tyburkiewicz, M., Litwa, E., Niemczyk, M., TotaGlowczyk, K., Willner, P., 2017. Dopaminergic mechanisms in memory consolidation and antidepressant reversal of a chronic mild stress-induced cognitive impairment'. Psychopharmacology (Berl) 234, 2571-2585.

Paxinos G.W.C., 1986. The rat brain in stereotaxic coordinates. New York: Academic Press.

Picciotto, M. R., 2010. Galanin and addiction. EXS 102, 195-208.

Pitsikas, N., Rigamonti. AE., Cella, SG., Muller, EE., 2003. The 5-HT 1A receptor antagonist WAY 100635 improves rats performance in different models of amnesia evaluated by the object recognition task. Brain Res. 983, 215-222.

Pompeiano, M., Palacios, J. M., Mengod, G., 1992. Distribution and cellular localization of mRNA coding for 5-HT1A receptor in the rat brain: correlation with receptor binding. J Neurosci 12, 440-453.

Pompeiano, M., Palacios, J. M., Mengod, G., 1994. Distribution of the serotonin 5-HT2 receptor family mRNAs: comparison between 5-HT2A and 5-HT2C receptors. Brain Res Mol Brain Res 23, 163-178.

Ragozzino, M. E., Detrick, S., Kesner, R. P., 2002. The effects of prelimbic and infralimbic lesions on working memory for visual objects in rats. Neurobiol Learn Mem 77, 29-43.

Ray, R. D., Zald, D. H., 2012. Anatomical insights into the interaction of emotion 
and cognition in the prefrontal cortex. Neurosci Biobehav Rev 36, 479-501.

Razani, H., Diaz-Cabiale, Z., Fuxe, K., Ogren, S. O., 2000. Intraventricular galanin produces a time-dependent modulation of $5-\mathrm{HT} 1 \mathrm{~A}$ receptors in the dorsal raphe of the rat. Neuroreport 11, 3943-3948.

Razani, H., Diaz-Cabiale, Z., Misane, I., Wang, F. H., Fuxe, K., Ogren, S. O., 2001. Prolonged effects of intraventricular galanin on a 5hydroxytryptamine $(1 \mathrm{~A})$ receptor mediated function in the rat. Neurosci Lett 299 , 145-149.

Reid, J. M., Jacklin, D. L., Winters, B. D., 2014. Delineating prefrontal cortex region contributions to crossmodal object recognition in rats. Cereb Cortex 24, 2108-2119.

Rinaldi, A., Romeo, S., Agustin-Pavon, C., Oliverio, A., Mele, A., 2010. Distinct patterns of Fos immunoreactivity in striatum and hippocampus induced by different kinds of novelty in mice. Neurobiol Learn Mem 94, 373-381.

Saenz del Burgo, L., Cortes, R., Mengod, G., Montana, M., Garcia del Cano, G., Salles, J., 2013. Chronic effects of corticosterone on GIRK1-3 subunits and 5HT1A receptor expression in rat brain and their reversal by concurrent fluoxetine treatment. Eur Neuropsychopharmacol 23, 229-239.

Tatemoto, K., Rokaeus, A., Jornvall, H., McDonald, T. J., Mutt, V., 1983. Galanin - a novel biologically active peptide from porcine intestine. FEBS Lett 164, 124-128.

Wang, S., Hashemi, T., He, C., Strader, C., Bayne, M., 1997. Molecular cloning and pharmacological characterization of a new galanin receptor subtype. Mol Pharmacol 52, 337-343.

Warburton, E. C., Brown, M. W., 2015. Neural circuitry for rat recognition memory. Behav Brain Res 285, 131-139.

Weiss, J. M., Bonsall, R. W., Demetrikopoulos, M. K., Emery, M. S., West, C. H., 1998. Galanin: a significant role in depression? Ann N Y Acad Sci 863, 364382.

\section{Figure Legends}

Figure 1: Schematic representation of the procedures followed to perform the behavioural experiments in the NOR (A) and OLM (B). In both tasks animals had a recovery period of 7 days prior to behavioural test and the animals performed the tasks in three phases, separated 24 hours from each other, where they explore freely during $10 \mathrm{~min}$ in the habituation phase without objects, $3 \mathrm{~min}$ in the training phase with two identical objects and finally $3 \mathrm{~min}$ in the test phase with one object changed in the NOR or one object in other location respect the training phase in the OLM. The pharmacological treatments were 
administered to the different groups of animals between the training and testing phases.

Figure 2: Representative microphotography of the colocalization of GALR1 and GALR2 in neurons of the mPFC. Double-immunolabeled for GALR1 (green, rhombus) and GALR2 (red, arrowhead) in mPFC. The colocalization of GALR1 and GALR2 is shown in the merge (orange-yellow, arrows). Escale bar, $50 \mu \mathrm{m}$.

Figure 3: Effects on the binding characteristics of 5-HT1AR agonist $[3 \mathrm{H}]-8$ OHDPAT in the mPFC after the coadministration of FLX $(10 \mathrm{mg} / \mathrm{kg})$ or GAL $(1-$ $15)(1 \mathrm{nmol})$ alone or in combination. FLX was administered sc 23,5 and 1,25h before sacrifice and GAL(1-15) or aCSF was injected icv 30min before. Saturation experiments were performed with ten concentrations of [3H]-8OHDPAT $(0.26-10 \mathrm{nM})$ in sections from the mPFC. Non-specific binding was defined as the binding in the presence of $10 \mathrm{mM}$ serotonin. The $\mathrm{Kd}(\mathbf{A})$ and the Bmax (B) values are shown as mean \pm SEM ( $n=6$ per group). In the control group the $\mathrm{Kd}(\mathrm{nM})$ value was $0.6 \pm 0.04$ and $B \max (\mathrm{fmol} / \mathrm{mg}$ prot) was $654 \pm 15$. ${ }^{*} p<0.05,{ }^{* *} p<0.01,{ }^{* * *} p<0.01$ versus $F L X(10 \mathrm{mg} / \mathrm{Kg})+G A L(1-15)(1 \mathrm{nmol})$ group and \#\#p<0.01, \#\#p<0.001 versus control group according to one way ANOVA followed by Newman-Keuls Multiple Comparison Test. (C) Representative autoradiograms from mPFC sections of rat showing a decrease of the affinity of the agonist for 5-HT1AR in the mPFC with a low concentration of the radioligand $(1 \mathrm{nM})$.

Figure 4: Effects of the coadministration of $F L X(10 \mathrm{mg} / \mathrm{kg})$ and $\mathrm{GAL}(1-15)$ $(1 \mathrm{nmol})$ on 5-HT1AR mRNA levels in the mPFC. FLX was administered sc 23, 5 and 1,25h before sacrifice and GAL(1-15) or aCSF was injected icv 30min before. (A) The values of optical density (O.D.), mean \pm SEM ( $n=6$ per group), are expressed as percentages respect of the control values $(100 \%)$. ${ }^{* *} p<0.01$ versus $\mathrm{FLX}(10 \mathrm{mg} / \mathrm{Kg})+\mathrm{GAL}(1-15)(1 \mathrm{nmol})$ group and \#\#p<0.01 versus control group according to one way ANOVA followed by Newman-Keuls Multiple 
Comparison Test. (B) Representative autoradiograms from mPFC showing the levels of mRNA coding for 5-HT1AR determined by in situ hybridization and the analyzed areas.

Figure 5: Graphic shows the ability of rats to discriminate the novel object at $24 \mathrm{~h}$ post-training after the administration of $F L X(10 \mathrm{mg} / \mathrm{kg})$ alone or in combination with a threshold doses of GAL(1-15)(1nmol) or GAL(1-15) plus the GALR2 antagonist M871(3nmol) in the NOR task. FLX or vehicle was administered sc 23, 5 and $1 \mathrm{~h}$ before the test. aCSF, GAL(1-15) and GAL(115)+M871 were injected icv 15 min before the test. Data represents mean \pm SEM of the DI during the $3 \mathrm{~min}$ of the test phase ( $\mathrm{n}=5-6$ rats per group). ${ }^{*} p<0.05$ versus $F L X(10 \mathrm{mg} / \mathrm{Kg})+G A L(1-15)(1 \mathrm{nmol})$ group and $\# p<0.01$ versus control group according to one way ANOVA followed by Newman-Keuls Multiple Comparison Test.

Figure 6: Graphic shows the ability of rats to discriminate the relocated object at $24 \mathrm{~h}$ post-training after the administration of $F L X(10 \mathrm{mg} / \mathrm{kg})$ alone or in combination with a threshold doses of GAL(1-15)(1nmol) in the OLM task. FLX or vehicle was administered sc 23,5 and $1 \mathrm{~h}$ before the test. aCSF, GAL(1-15) were injected icv $15 \mathrm{~min}$ before the test. Data represents mean \pm SEM of the DI during the $3 \mathrm{~min}$ of the test phase ( $\mathrm{n}=6$ rats per group). No statistically significant difference was observed between the experimental groups according to one way ANOVA followed by Newman-Keuls Multiple Comparison Test.

Table 1: Table shows A) the locomotor activity and total exploration time of the rats in the NOR and OLM tasks after the administration of FLX $(10 \mathrm{mg} / \mathrm{kg})$ alone or in combination with a threshold dose of $\mathrm{GAL}(1-15)(1 \mathrm{nmol})$ or GAL(1$15)(1 \mathrm{nmol})+\mathrm{M} 871(3 \mathrm{nmol})$ during the test phase. FLX or vehicle was administered sc 23,5 and $1 \mathrm{~h}$ before the test. aCSF or GAL(1-15) were injected icv $15 \mathrm{~min}$ before the test. B) Discrimination index, locomotor activity and total exploration time of the rats in the NOR tasks after the administration of GAL(1- 
$15)(1 \mathrm{nmol})$ or $\mathrm{M} 871(3 \mathrm{nmol})$ alone during the test phase. Vehicle was administered sc 23, 5 and $1 \mathrm{~h}$ before the test. aCSF, GAL(1-15) or M871 were injected icv $15 \mathrm{~min}$ before the test. No statistically significant difference was observed vs control group according to one way ANOVA followed by Bonferroni's Multiple Comparison Test.

Table 2: Total object exploration time by groups in the training phase of the NOR and OLM tasks before the administration of the treatments. No statistically significant difference was observed between the experimental groups according to one way ANOVA followed by Newman-Keuls Multiple Comparison Test. 
Table 1

\begin{tabular}{|c|c|c|c|}
\hline \multicolumn{2}{|l|}{ A } & \multirow{2}{*}{$\begin{array}{c}\begin{array}{c}\text { Exploration } \\
\text { Time (s) }\end{array} \\
23.4 \pm 2.2\end{array}$} & \multirow{2}{*}{$\begin{array}{c}\begin{array}{c}\text { Locomotor } \\
\text { activity }(\mathrm{cm})\end{array} \\
2550 \pm 343\end{array}$} \\
\hline NOR & Control & & \\
\hline & $\mathrm{FLX}(10 \mathrm{mg} / \mathrm{Kg})$ & $24.3 \pm 2.4$ & $2870 \pm 251$ \\
\hline & $\begin{array}{l}\mathrm{FLX}(10 \mathrm{mg} / \mathrm{Kg})+ \\
\text { GAL }(1-15)(1 \mathrm{nmol}\end{array}$ & $18.3 \pm 1.9$ & $2662 \pm 264$ \\
\hline & $\begin{array}{l}\text { FLX }(10 \mathrm{mg} / \mathrm{Kg})+ \\
\text { GAL }(1-15)(1 \mathrm{nmol})+ \\
\text { M871(3nmol) }\end{array}$ & 15.5 & $2030 \pm 107$ \\
\hline \multirow[t]{3}{*}{ OLM } & Control & $20.8 \pm 5$ & $2471 \pm 335$ \\
\hline & $\mathrm{FLX}(10 \mathrm{mg} / \mathrm{Kg})$ & $23.78 \pm 1.7$ & $2707 \pm 104$ \\
\hline & $\begin{array}{l}\mathrm{FLX}(10 \mathrm{mg} / \mathrm{Kg})+ \\
\text { GAL }(1-15)(1 \mathrm{nmmol}\end{array}$ & $23.47 \pm 3.8$ & $1985 \pm 276$ \\
\hline
\end{tabular}

\begin{tabular}{l|c|c|c|c}
\hline \multirow{2}{*}{ B } & $\begin{array}{c}\text { Exploration } \\
\text { Time }(\mathrm{s})\end{array}$ & $\begin{array}{c}\text { Locomotor } \\
\text { activity }(\mathrm{cm})\end{array}$ & $\begin{array}{c}\text { DI } \\
\text { (discrimination } \\
\text { index) }\end{array}$ \\
\hline \multirow{2}{*}{ NOR } & Control & $23.6 \pm 2.9$ & $2463 \pm 233$ & $0.30 \pm 0.04$ \\
\cline { 2 - 5 } & GAL(1-15)(1nmol) & $22.9 \pm 2.9$ & $2663 \pm 333$ & $0.31 \pm 0.07$ \\
\cline { 2 - 5 } & M871(3nmol) & $27.2 \pm 1.3$ & $2599 \pm 290$ & $0.27 \pm 0.06$ \\
\hline
\end{tabular}


Table 2: Total object exploration time by groups in the training phase.

\begin{tabular}{c|c|c|c|c|c|c}
\hline \multicolumn{3}{c|}{ OLM } & \multicolumn{3}{c}{ NOR } \\
\hline Control & FLX(10mg/Kg) & $\begin{array}{c}\text { FLX }(10 \mathrm{mg} / \mathrm{Kg})+ \\
\mathrm{GAL}(1-15)(1 \mathrm{nmol})\end{array}$ & Control & FLX(10mg/Kg) & $\begin{array}{c}\mathrm{FLX}(10 \mathrm{mg} / \mathrm{Kg})+ \\
\mathrm{GAL}(1-15)(1 \mathrm{nmol})\end{array} \begin{array}{c}\mathrm{FLX}(10 \mathrm{mg} / \mathrm{Kg})+ \\
\mathrm{GAL}(1-15(1 \mathrm{nmol}) \\
+\mathrm{M} 871(3 \mathrm{nmol})\end{array}$ \\
\hline $22.1 \pm 5.4$ & $29.5 \pm 5.1$ & $23.7 \pm 3.2$ & $31.2 \pm 4.5$ & $34.2 \pm 3.7$ & $25.6 \pm 3.9$ \\
\hline
\end{tabular}


Figure 1

A NOR

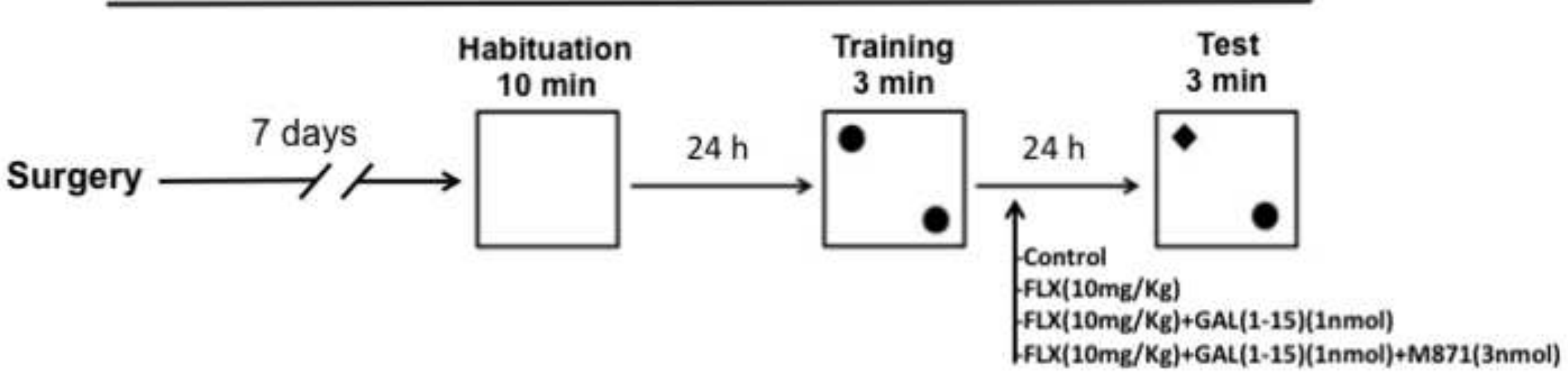

B OLM

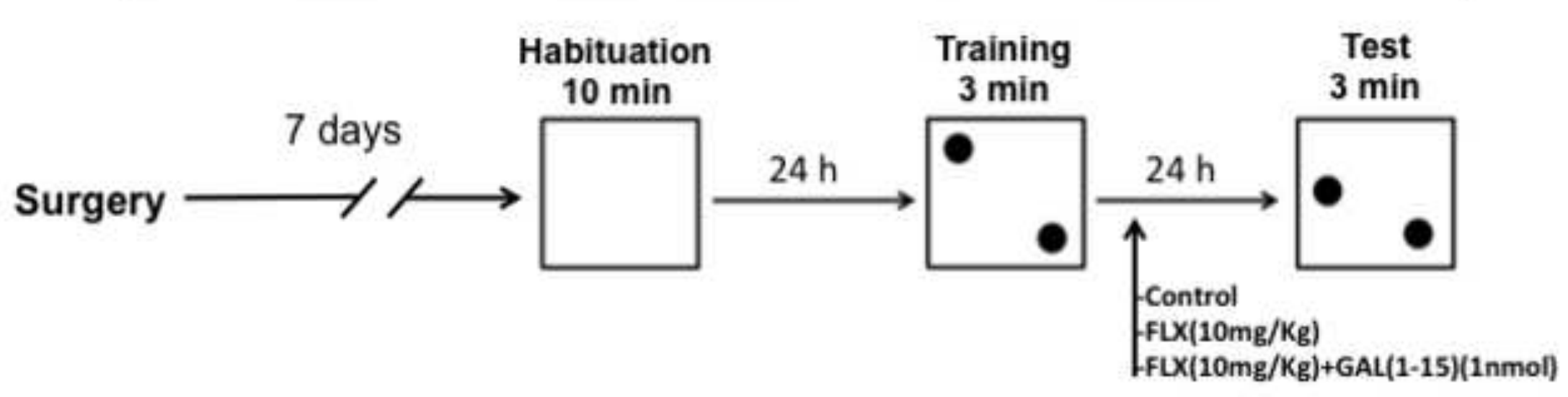


Click here to download high resolution image

\section{Figure 2}

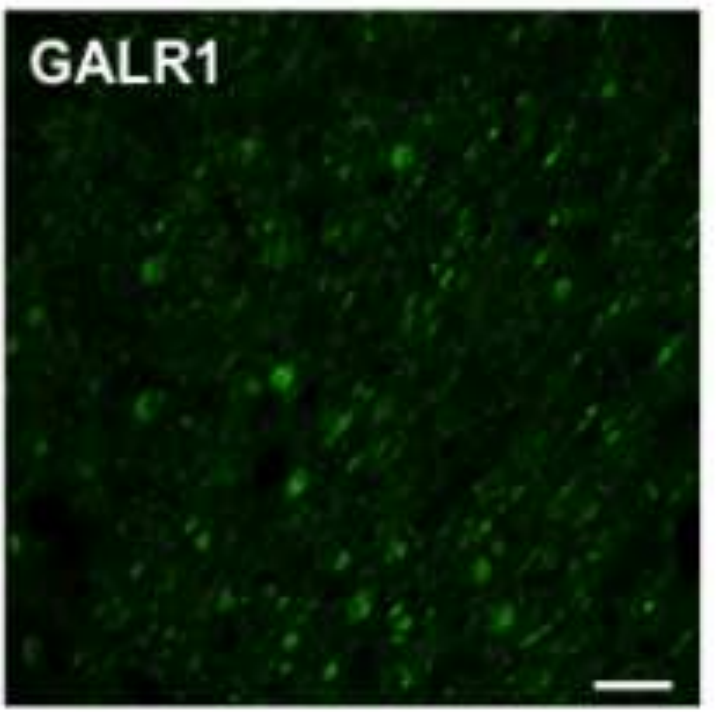

\section{GALR2}

7

\section{Merge}
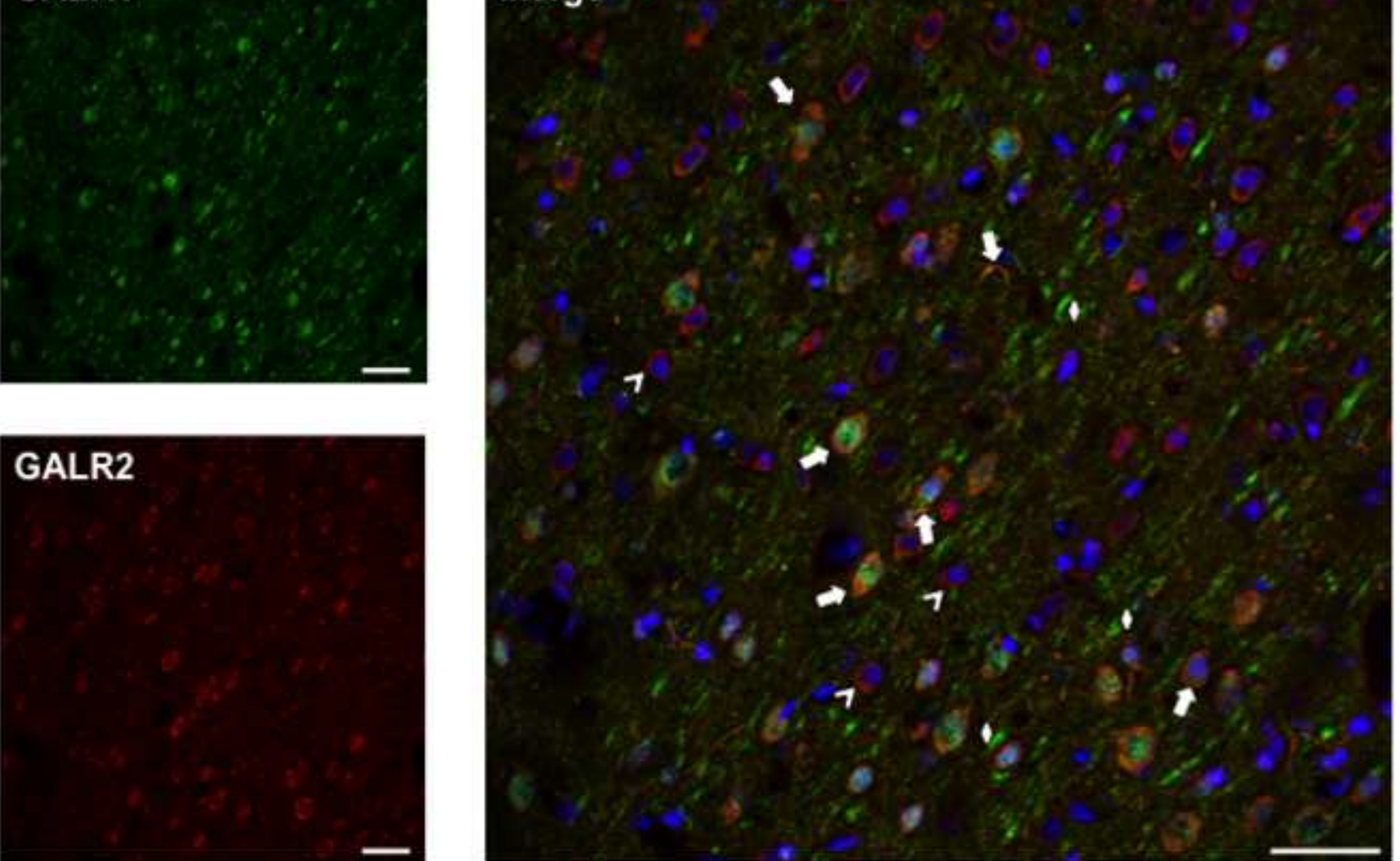
Click here to download high resolution image

Figure $3 \quad$ A

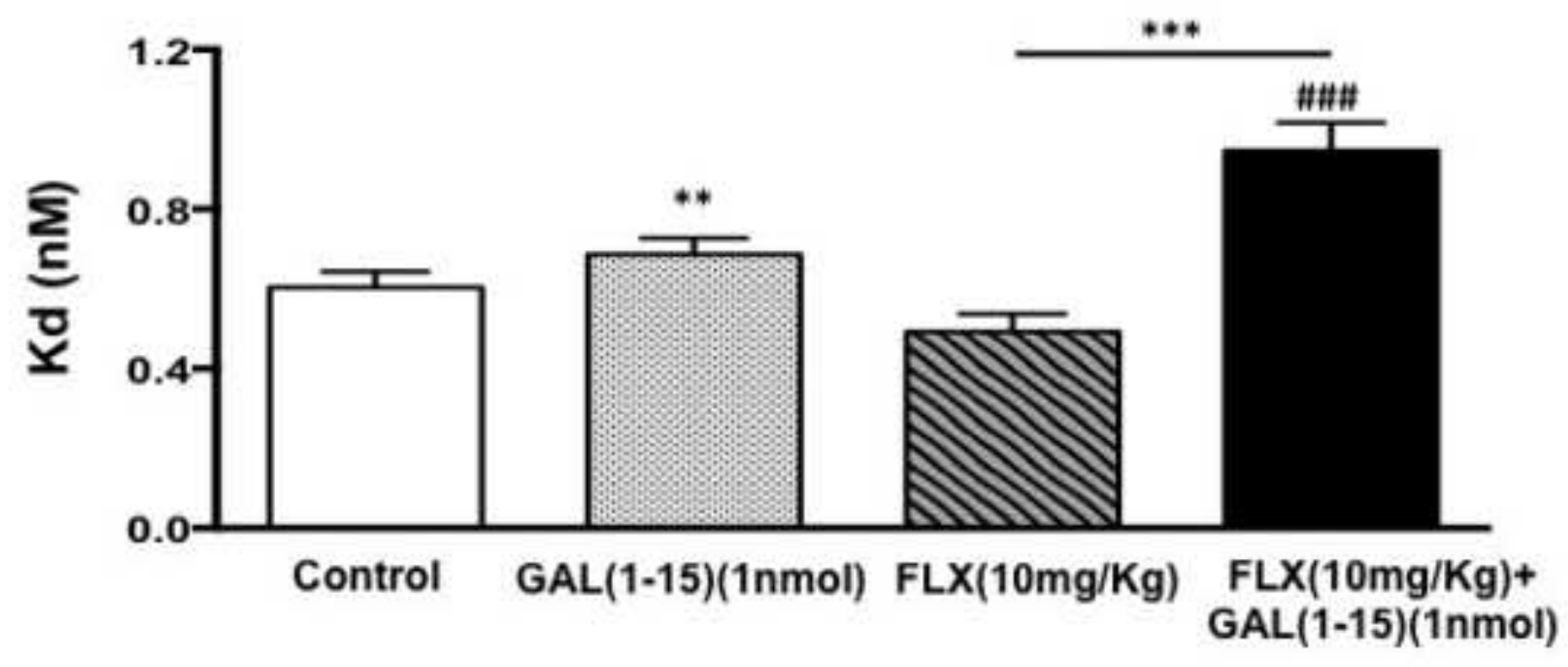

B

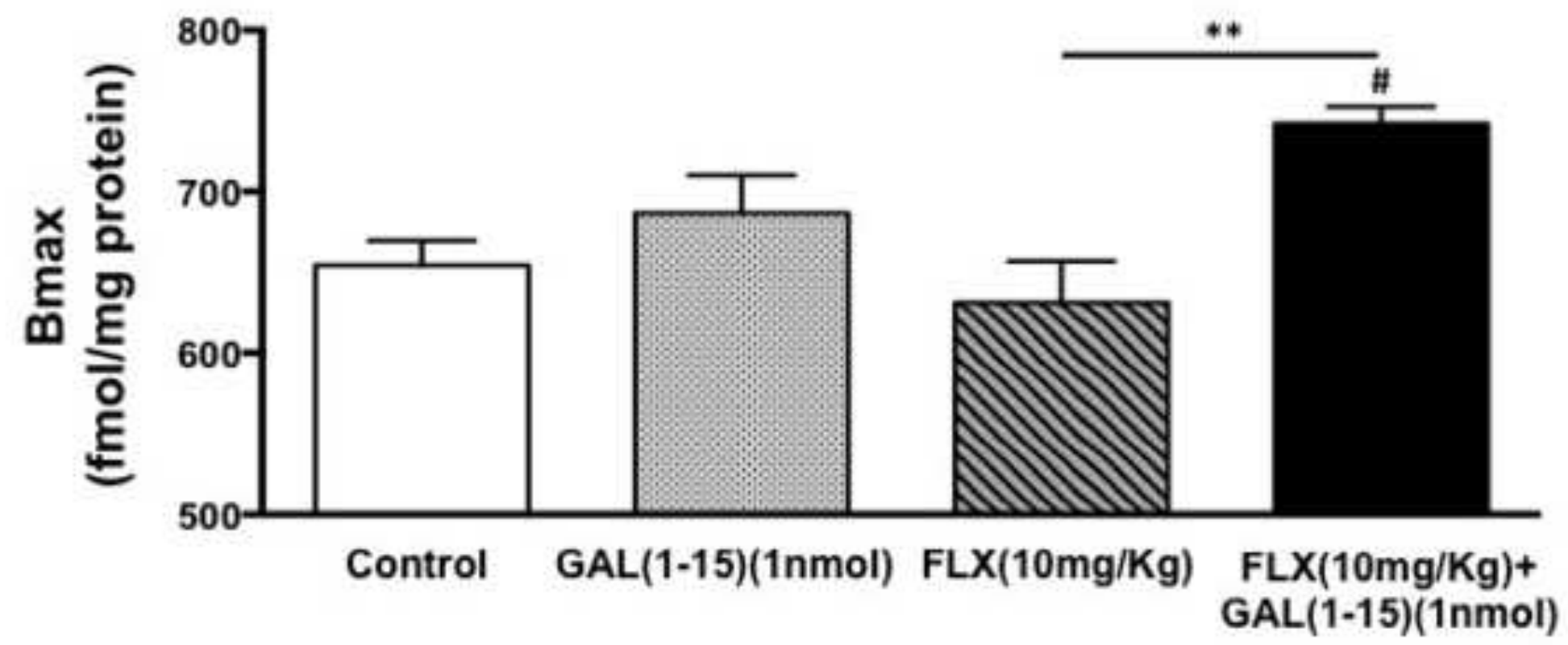


Figure-3c
Click here to download high resolution image

C

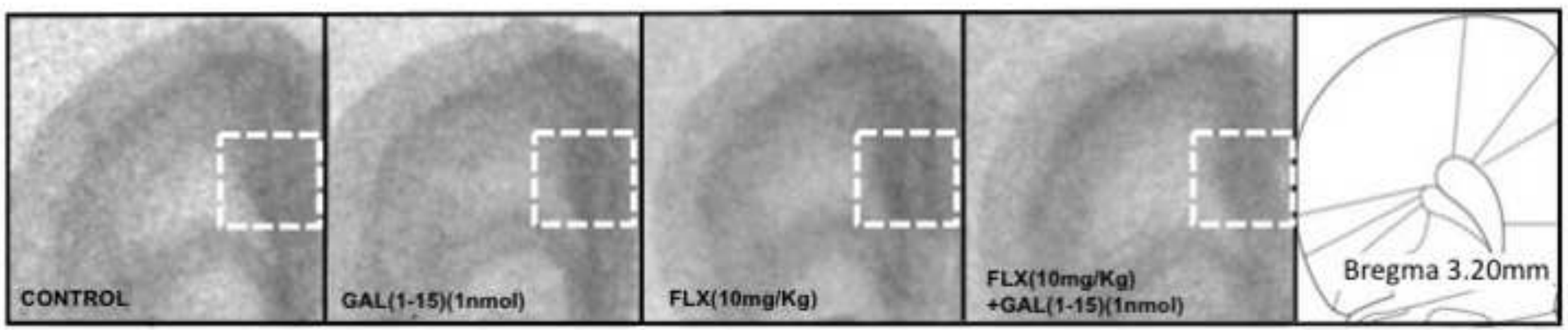


Click here to download high resolution image

Figure 4

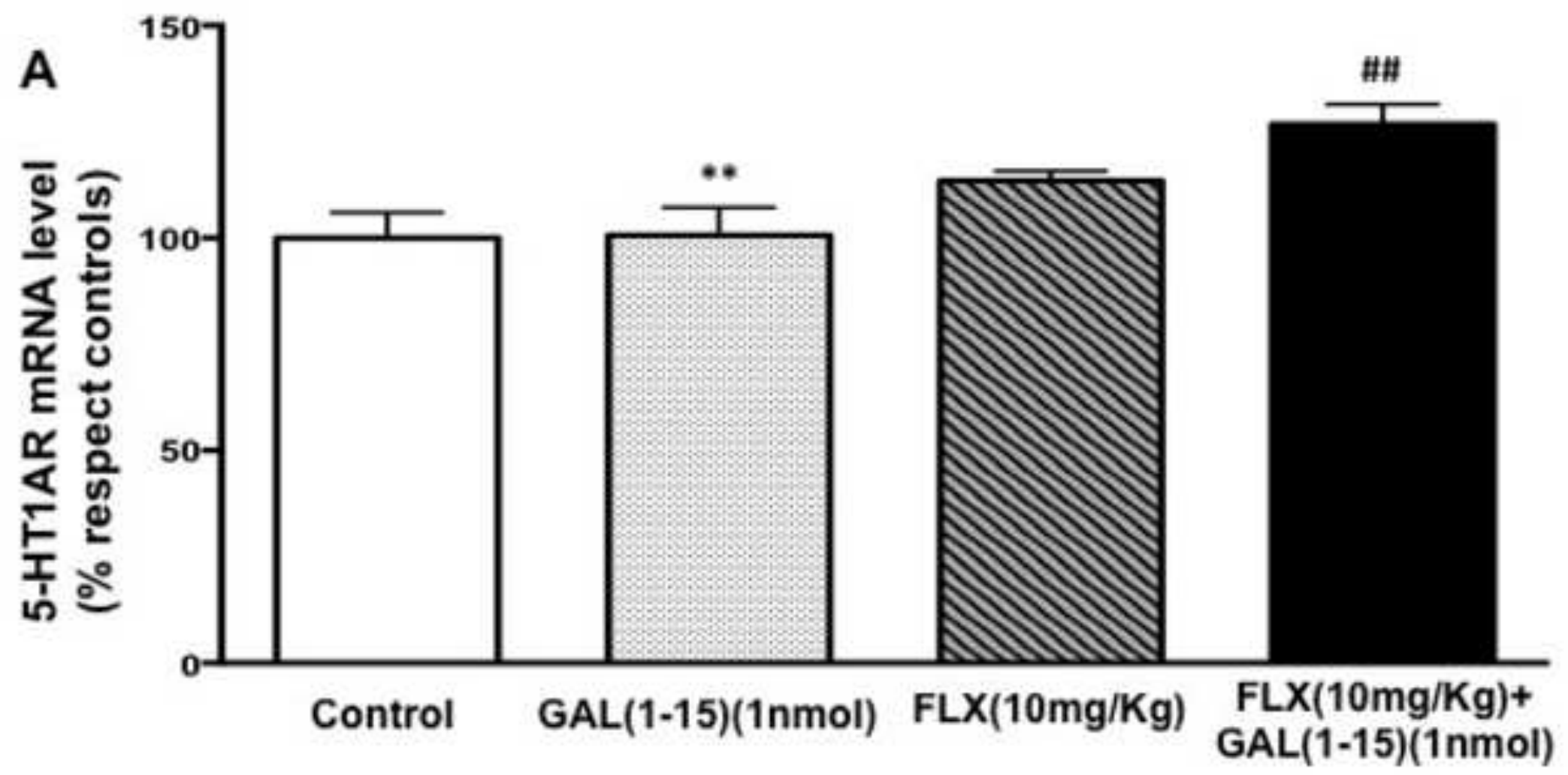

B

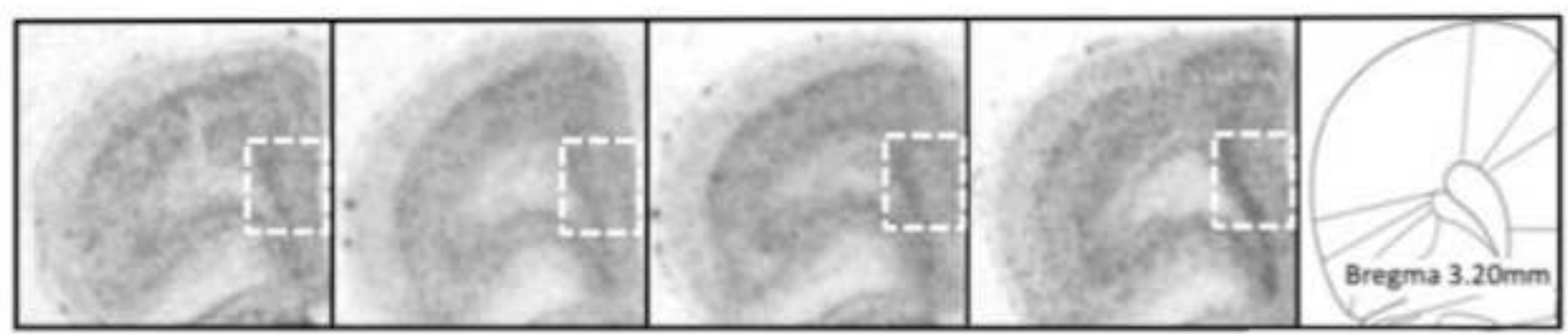


Figure 5

\section{NOR}

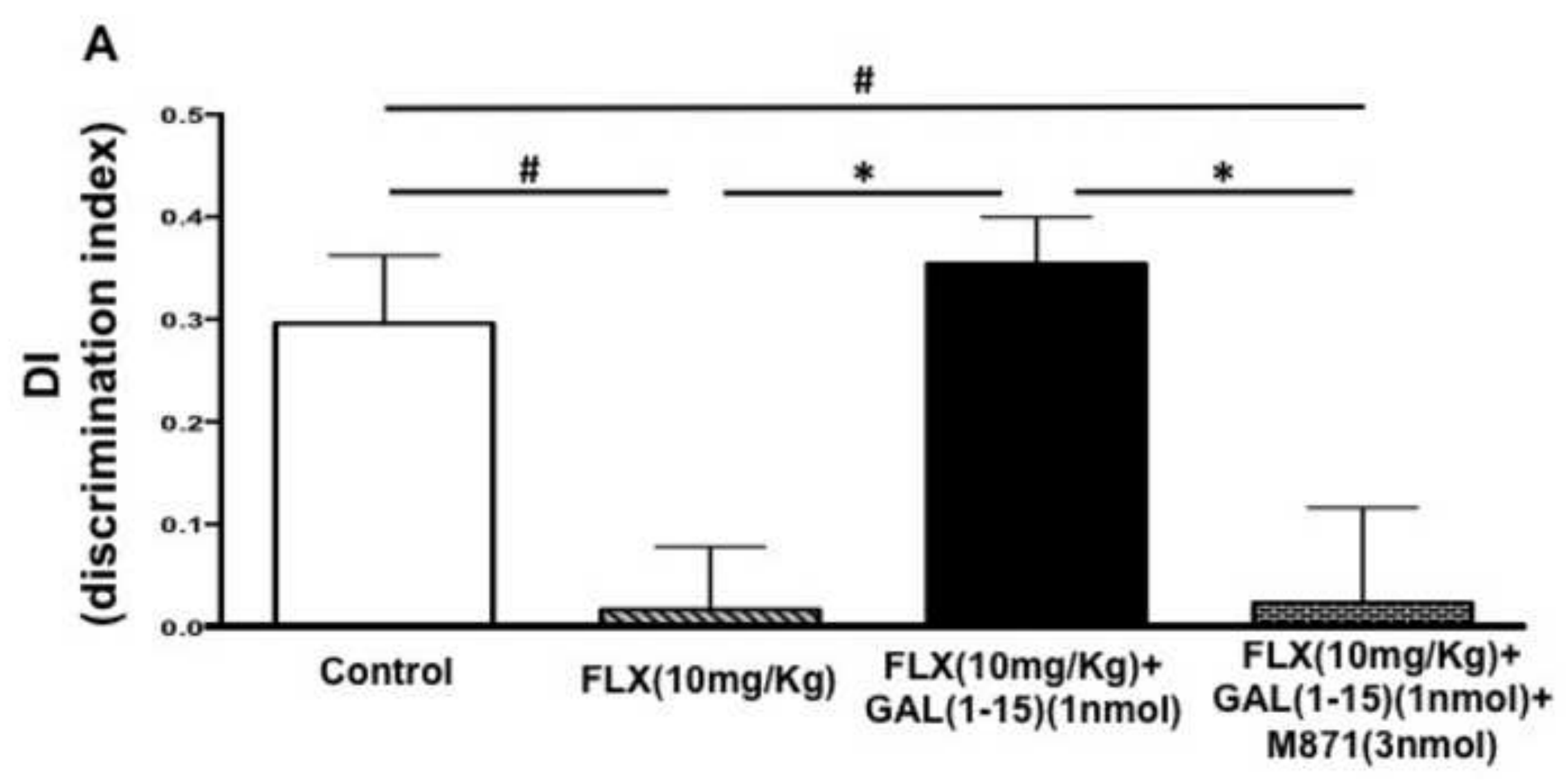




\section{Figure 6}

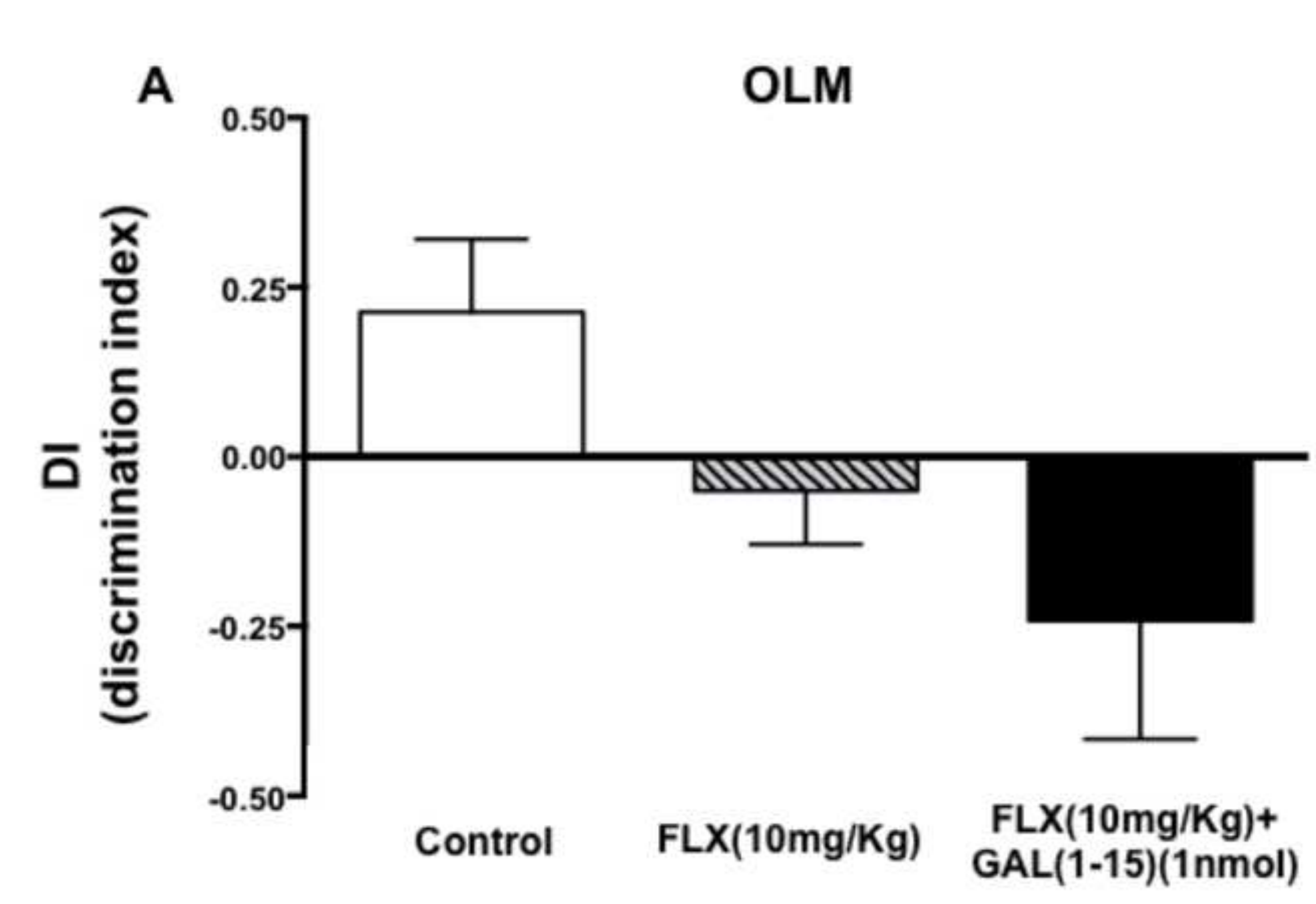

